\title{
Design of log house for agro-tourism from ain wood
}

\section{S.P. DIVEKAR, S.K. JAIN, CHANDAN KUMAR, R.B. MAHADIK AND V.M. DAWARE}

See end of the Paper for authors' affiliation

Correspondence to :

\section{S.P. DIVEKAR}

Department of Farm Structures, College of Agricultural Engineering and Technology, Dapoli, RATNAGIRI (M.S.) INDIA
- ABSTRACT : The presence of log house in agro-tourism is one of type of attraction to the tourists to come for agro-tourism. The tourists come for tourism and they stay in log house. The main advantage of a log house is a healthy living environment. The log house is made up with the locally available wood or light weight wood. The demand for wooden products is continuously increasing day by day. Wood is exposed to both periodic water absorption and desorption process. Understanding water absorption and desorption in wood are of practical importance since they also affect the mechanical properties of the product. In residential building and in industrial application some of the components are often wood (Ostman, 1985). For the purpose of the study, Agro-tourism for farmers is considered as a range of activities, services and amenities provided by farmers and rural people to attract tourist to their area in order to generate extra income for their businesses. Agro-tourism for tourists is considered as anything that connects tourists with the heritage, natural resource or culinary experiences unique to the agricultural industry or a specific region of the country's rural areas. The designed log house was safe from different loads point of view.

- KEY WORDS : Log house, Dead load, Live load

- HOW TO CITE THIS PAPER : Divekar, S.P., Jain, S.K., Kumar, Chandan, Mahadik, R.B. and Daware, V.M. (2017). Design of log house for agro-tourism from ain wood. Internat. J. Agric. Engg., 10(1) : 152-158, DOI: 10.15740/HAS/IJAE/10.1/152-158. 